\title{
Body mass index associated with onset and progression of osteoarthritis of the knee but not of the hip: The Rotterdam Study
}

\author{
M Reijman, H A P Pols, A P Bergink, J M W Hazes, J N Belo, A M Lievense, S M A Bierma-Zeinstra
}

See linked editorial, p 141

Ann Rheum Dis 2007;66:158-162. doi: 10.1136/ard.2006.053538

See end of article for authors' affiliations

Correspondence to:

Max Reijman, Department of

Orthopedics, Erasmus

Medical Center, PO Box

2040, 3000 CA Rotterdam,

The Netherlands;

m.reijman@erasmusmc.nl

Accepted 7 July 2006

Published Online First

12 July 2006
Objective: To investigate the relationship between body mass index (BMI) and the incidence and progression of radiological knee as well as of radiological hip osteoarthritis.

Design: Cohort study.

Setting: Population based.

Participants: 3585 people aged $\geqslant 55$ years were selected from the Rotterdam Study, on the basis of the availability of radiographs of baseline and follow-up.

Main outcome measures: Incidence of knee or hip osteoarthritis was defined as minimally grade 2 at followup and grade 0 or 1 at baseline. The progression of osteoarthritis was defined as a decrease in joint space width.

Methods: $x$ Rays of the knee and hip at baseline and follow-up (mean follow-up of 6.6 years) were evaluated. BMI was measured at baseline.

Results: A high BMI $\left(>27 \mathrm{~kg} / \mathrm{m}^{2}\right)$ at baseline was associated with incident knee osteoarthritis (odds ratio (OR) 3.3), but not with incident hip osteoarthritis. A high BMI was also associated with progression of knee osteoarthritis (OR 3.2). For the hip, a significant association between progression of osteoarthritis and BMI was not found.

Conclusion: On the basis of these results, we conclude that BMI is associated with the incidence and progression of knee osteoarthritis. Furthermore, it seems that BMl is not associated with the incidence and progression of hip osteoarthritis.
O steoarthritis of the knee and hip is one of the main causes of disability among elderly people, and the prevalence of osteoarthritis will increase with the ageing of the Western society. ${ }^{2}$

Osteoarthritis is a multifactorial disease involving firstly, systemic factors (eg, age, sex, hormones, genetics and nutritional factors), secondly, intrinsic joint vulnerabilities (eg, previous damage, bridging muscle weakness, malalignment and laxity) and finally, extrinsic factors acting on joints (eg, specific injurious activities and obesity) as described by Dieppe and Felson. ${ }^{3}$ Obesity seems to be an important modifiable risk factor for the onset of osteoarthritis of the knee. Several casecontrol studies ${ }^{4-9}$ and population-based studies ${ }^{10-12}$ consistently reported a relationship between overweight and the onset of radiographic osteoarthritis (ROA) of the knee. However, this relationship seems to be less clear for ROA of the hip, although a relationship between obesity and a total hip replacement was reported. ${ }^{3}{ }^{33-18}$

So far, some population-based studies have investigated the relationship between body mass index (BMI; weight $(\mathrm{kg}) /$ height ${ }^{2}\left(\mathrm{~m}^{2}\right)$ ) and progression of ROA of the knee (in small study populations; $<500$ people), with inconsistent results. ${ }^{4}{ }^{19-24}$ A recent review of the available literature on the prognostic factors for progression of hip osteoarthritis ${ }^{25}$ showed that obesity seems to have no relationship with the progression of hip osteoarthritis (small study populations and nearly all casecontrol designs).

The inconsistent results found for the knee and the inconsistencies between the hip and knee can be explained by different study designs, different definitions of progression or different study populations. There is a clear need to study the relationship between BMI and incidence and progression of both knee and hip osteoarthritis in a single population based study.

This study investigated the relationship between BMI and incidence and progression of radiological knee osteoarthritis as well as of radiological hip osteoarthritis, in a large populationbased cohort with a long-term follow-up period.

\section{PARTICIPANTS AND METHODS}

The study population consisted of participants of the Rotterdam Study, a prospective cohort of men and women aged $\geqslant 55$ years. The objective of the Rotterdam Study is to investigate the incidence of, and risk factors for, chronic disabling diseases; the rationale and study design have been described previously. ${ }^{26}$ Written informed consent was obtained from each participant. The medical ethics committee of the erasmus Medical Center, Rotterdam, The Netherlands, approved this study.

All 10275 inhabitants of the district of Ommoord in Rotterdam, The Netherlands, were invited to participate. The response rate was $78 \%$, resulting in 7983 participants in this study. Of these participants, 6450 visited a research centre for a baseline examination and 3585 of these revisited the centre after 6 years' follow-up.

To study the association between incident (knee and hip) osteoarthritis and BMI, we included only knees and hips with a Kellgren and Lawrence score at baseline of grade 0 or 1 for the analyses, resulting in 2570 knees (of 1372 participants) and 5481 hips (of 2852 participants).

To study the association between (knee and hip) progression of osteoarthritis and BMI, we included only knees and hips

Abbreviations: $\mathrm{BMI}$, body mass index; JSN, joint space narrowing; JSW, joint space width; ROA, radiographic osteoarthritis 
Table 1 Baseline characteristics of the study population with incident and progression of knee and hip radiographic osteoarthritis

\begin{tabular}{|c|c|c|c|c|}
\hline & \multicolumn{2}{|c|}{$\begin{array}{l}\text { Incident population (K\&L } \leqslant \text { grade } 1 \text { at } \\
\text { baseline) }\end{array}$} & \multicolumn{2}{|c|}{$\begin{array}{l}\text { Progression population (K\&L } \geqslant \text { grade } 1 \\
\text { and } \leqslant \text { grade } 3 \text { at baseline) }\end{array}$} \\
\hline & Knee & Hip & Knee & Hip \\
\hline $\begin{array}{l}\text { Number of participants } \\
\text { (number of joints) }\end{array}$ & $1372(2570)$ & $2852(5481)$ & $532(865)$ & $1676(2535)$ \\
\hline Mean (SD) age (years) & $66.3(6.7)$ & $65.7(6.7)$ & $68.6(7.0)$ & $66.1(6.9)$ \\
\hline Sex (\% women) & 57.7 & 57.9 & $68.4^{\circ}$ & 52.1 \\
\hline Mean (SD) BMI, $\left(\mathrm{kg} / \mathrm{m}^{2}\right)$ & $26.0(3.5)$ & $26.3(3.6)$ & $27.4(3.9)$ & $26.3(3.5)$ \\
\hline Incident ROA (\%) & 5.5 & 3.9 & - & - \\
\hline \multicolumn{5}{|l|}{ Progression of ROA } \\
\hline$J S N \geqslant 1 \mathrm{~mm}(\%)$ & - & - & 21.8 & 8.7 \\
\hline$J S N \geqslant 1.5 \mathrm{~mm}(\%)$ & - & - & 8.1 & 2.5 \\
\hline Increase in K\&L (\%) & - & - & 11.4 & 10.1 \\
\hline \multicolumn{5}{|c|}{ 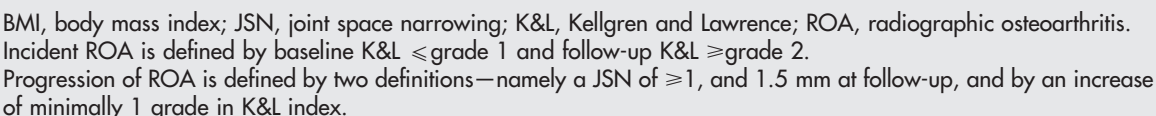 } \\
\hline
\end{tabular}

with a presence of radiographic osteoarthritic signs at baseline defined by a Kellgren and Lawrence score at baseline of grade 1, 2 or 3 for the analyses, resulting in 865 knees (of 532 participants) and 2535 hips (of 1676 participants).

The numbers of the knees included are smaller as only a random selection of radiographs of the knee at baseline and at follow-up were evaluated (1585 participants).

The baseline measurements were conducted between 1990 and 1993, and the follow-up measurements between 1996 and 1999 , with a mean follow-up time of 6.6 years.

As our study population had to be mobile enough to visit the research centre at baseline and at follow-up, and survived the follow-up period, compared with the total population of the Rotterdam Study, it was younger, had a lower prevalence of lower limb disability and a lower prevalence of hip pain than reported earlier. ${ }^{27}$

\section{Radiographic assessment}

Weight-bearing anteroposterior radiographs of the hip and knee were obtained at $70 \mathrm{KV}$ (focus 1.8 , focus to film distance $120 \mathrm{~cm}$, Fuji High Resolution G $35 \times 43 \mathrm{~cm}$ film). Radiographs of the pelvis were obtained with both feet in $10^{\circ}$ internal rotation and the $x$ ray beam centred on the umbilicus, and radiographs of the knee with the patellae in central position. A trained reader (MR) evaluated the radiographs of the hip obtained at baseline and at follow-up, unaware of the clinical status of the patients. Two trained readers (EO and APB) independently evaluated the radiographs of the knee, also unaware of the clinical status of the patients. All radiographs of

Table 2 Association between incident radiographic osteoarthritis and body mass index, for the knee $(n=1372)$ and hip $(\mathrm{n}=2852)$

\begin{tabular}{|c|c|c|c|c|}
\hline \multirow[b]{2}{*}{ BMI $\left(\mathrm{kg} / \mathrm{m}^{2}\right)$} & \multicolumn{2}{|l|}{ Knee } & \multicolumn{2}{|l|}{ Hip } \\
\hline & $\begin{array}{l}\text { Incident } \\
\text { ROA (\%) }\end{array}$ & OR $(95 \% \mathrm{Cl})$ & $\begin{array}{l}\text { Incident } \\
\text { ROA (\%) }\end{array}$ & OR $(95 \% \mathrm{Cl})$ \\
\hline$\leqslant 25$ & 3.0 & 1 & 3.5 & 1 \\
\hline$>25-27.5$ & 5.2 & $1.9(1.2$ to 3.2$)$ & 4.5 & $1.3(0.9$ to 1.9$)$ \\
\hline$>27.5$ & 9.3 & 3.3 (2.1 to 5.3 ) & 4.0 & $1.0(0.7$ to 1.5$)$ \\
\hline
\end{tabular}

$\mathrm{BMI}$, body mass index; ROA, radiographic osteoarthritis. ORs were adjusted for age, sex and follow-up time. Incident ROA is defined by baseline Kellgren and Lawrence $\leqslant$ grade 1 and follow-up Kellgren and Lawrence $\geqslant$ grade 2 the hip and knee were grouped per patient and read by pairs in chronological order, the order being known to the reader (chronologically ordered reading procedure). ${ }^{28}$

\section{Incident ROA}

We defined incident ROA of the knee or hip as a baseline Kellgren and Lawrence index of grade 0 or 1 , and grade $\geqslant 2$ at follow-up measurement.

\section{Progression of ROA}

We used two definitions of progression of knee or hip ROAnamely (1) a joint space narrowing (JSN) of $\geqslant 1 \mathrm{~mm}$ and of $\geqslant 1.5 \mathrm{~mm}$ at follow-up and (2) an increase of minimally 1 grade of Kellgren and Lawrence. ${ }^{27}$

JSN was defined as the joint space width (JSW) of baseline minus the JSW of follow-up. Owing to the absence of consensus on the cut-off point for JSN, we used different cutoff points-namely $\mathrm{l}$ and $1.5 \mathrm{~mm}$ decreases in the JSW between baseline and follow-up.

At baseline and follow-up, the minimal JSW of the hip joints was measured using a $0.5 \mathrm{~mm}$ graduated magnifying glass laid directly over the radiograph. ${ }^{29}$ For the knee the medial and lateral compartments were measured, and for the hip the lateral, superior and axial compartments were measured, as described by Croft et al. ${ }^{29}$ The inter-rater reliability of the hip was 0.68 for Kellgren and Lawrence ( $\kappa$ statistics) and 0.85 (intraclass correlation coefficient) for the minimal JSW, as reported earlier. ${ }^{27}$ The radiographs of the knee were scored for radiographic osteoarthritis by two independent observers. After each set of 150 radiographs, the scores of the two readers were evaluated. Whenever the Kellgren and Lawrence score differed, the two readers met to read the radiographs, and a consensus score was determined. ${ }^{30} 31$

\section{Clinical measures}

At baseline, trained interviewers conducted an extensive home interview dealing with demographic characteristics, medical history, risk factors for chronic diseases and drug use. At the research centre, a clinical examination was performed. Height and weight were measured with participants wearing indoor clothing without shoes, and BMI was calculated.

\section{Statistical analysis}

Associations between baseline BMI and incidence and progression of knee and hip ROA were assessed using logistic 
Table 3 Associations between progression of knee osteoarthritis and body mass index $(n=532)$

\begin{tabular}{|c|c|c|c|c|c|c|}
\hline \multirow[b]{2}{*}{ BMI $\left(\mathrm{kg} / \mathrm{m}^{2}\right)$} & \multicolumn{2}{|l|}{$\geqslant 1 \mathrm{~mm}$} & \multicolumn{2}{|l|}{$\geqslant 1.5 \mathrm{~mm}$} & \multicolumn{2}{|l|}{ Increase in $\mathrm{K} \& \mathrm{~L}$} \\
\hline & Progression (\%) & OR $(95 \% \mathrm{Cl})$ & Progression (\%) & OR $(95 \% \mathrm{CI})$ & Progression (\%) & OR $(95 \% \mathrm{Cl})$ \\
\hline$\leqslant 25$ & 18.2 & 1 & 3.6 & 1 & 7.8 & 1 \\
\hline$>25-27.5$ & 20.8 & $1.2(0.6$ to 2.4$)$ & 7.5 & 2.3 (0.7 to 7.7$)$ & 7.8 & $1(0.5$ to 2.0$)$ \\
\hline$>27.5$ & 24.5 & $1.4(0.8$ to 2.6$)$ & 11.2 & $3.2(1.1$ to 9.7$)$ & 15.6 & 2.1 (1.2 to 3.7$)$ \\
\hline
\end{tabular}

BMI, body mass index; K\&L, Kellgren and Lawrence.

ORs were adjusted for age, sex and follow-up time.

Progression is defined by two definitions - namely a joint space narrowing of $\geqslant 1$, and $1.5 \mathrm{~mm}$ at follow-up, and by an increase of minimally 1 grade in K\&L index.

regression analysis to calculate ORs, by means of generalised estimating equations. This procedure was used because this method takes into account the correlation between the left and right knees or hips, using each patient as the observation unit and the knees or hips as repeated measurements. ${ }^{32}$ BMI was divided into three groups-namely $\leqslant 25,25-27.5$ and $>27.5 \mathrm{~kg} / \mathrm{m}^{2}$. We used a low BMI $\left(\leqslant 25 \mathrm{~kg} / \mathrm{m}^{2}\right)$ as reference group for all analyses.

To assess the association between baseline BMI and incidence and progression of knee and hip ROA, we calculated ORs adjusted for age, sex and follow-up time.

A ( two-sided) p value of 0.05 was considered significant in all analyses. We used SAS software V.8.2 and SPSS V.11.0.

\section{RESULTS}

Table 1 presents the baseline characteristics of the study population used to assess the association between BMI and incident ROA ( $\leqslant$ grade 1 of Kellgren and Lawrence index) and the study population used to assess the association between BMI and progression of ROA ( $\geqslant$ grade 1 of Kellgren and Lawrence index) of the knee and hip. In the first study subpopulation, $5.5 \%$ and $3.9 \%$ developed incident ROA of the knee and hip after a mean follow-up time of 6.6 years. After the follow-up period, we found for progression (as defined by JSN of $\geqslant 1$ and $1.5 \mathrm{~mm}$, and by an increase of minimally 1 grade of Kellgren and Lawrence) of the knee a percentage of $21.8 \%, 8.1 \%$ and $11.4 \%$, respectively, and of the hip $8.7 \%, 2.5 \%$ and $10.1 \%$, respectively.

Table 2 shows the associations between incident ROA and BMI. The data show that a high BMI $\left(>27 \mathrm{~kg} / \mathrm{m}^{2}\right)$ as measured at baseline was associated with incident knee ROA, but not with incident hip ROA. The presented ORs are adjusted for age, sex and follow-up time. We observed a clear trend that the higher the BMI, the stronger the association with incident knee ROA. Again, this trend was absent in hip ROA.

Table 3 presents the associations between progression of knee ROA and BMI. We found that a high BMI $\left(>27.5 \mathrm{~kg} / \mathrm{m}^{2}\right)$ was significantly associated with progression of knee ROA defined by JSN $\geqslant 1.5 \mathrm{~mm}$ and by an increase of minimally 1 grade in the Kellgren and Lawrence index after the follow-up period.
However, this was not the case if JSN $\geqslant 1 \mathrm{~mm}$ was used as a definition for progression.

For the hip, we did not find a significant association between the progression of ROA and BMI (table 4). For all three definitions, the risk estimates were not significant.

\section{DISCUSSION}

In this large population-based prospective cohort study with a long-term follow-up, we found that BMI is a strong independent determinant of incident knee ROA, but not of incident hip ROA. It seems that BMI is also a moderate determinant of progression of knee ROA but not of progression of hip ROA.

This study confirmed that obesity is an important risk factor for the onset of ROA of the knee. The results of this study indicate that overweight is not related to the onset of ROA of the hip. Two case-control studies investigated the relationship between BMI and an incident total hip replacement during the follow-up period and reported conflicting results. ${ }^{17}{ }^{18}$ So far, no studies have been published that investigated the relationship between BMI and incident ROA of the hip in a longitudinal study.

The strength of this study is that the relationship between BMI and incidence and progression of ROA has been investigated in a single study with a similar population and a similar design. Therefore, the reported association between BMI and progression of knee ROA was independent of the definition used for progression. We used two definitions of progression of ROA-namely a JSN and an increase in the Kellgren and Lawrence index. For both definitions, we found a moderate association between BMI and progression of knee ROA. So far, studies that have investigated this topic have reported inconsistent results. ${ }^{49-24}$ We confirmed in this large study that BMI is not related to the progression of hip ROA, as suggested earlier by Lievense et al. ${ }^{25}$

The fact that participants had to be mobile enough to visit the research centre at baseline and at follow-up, and survive the follow-up period (mean 6.6 years), led to the selection of a younger and healthier population. Compared with the total Rotterdam Study population, our study population was younger, had a lower prevalence of lower limb disability, and a lower prevalence of knee and hip pain. Therefore, in this

Table 4 Associations between progression of hip osteoarthritis and body mass index $(n=1676)$

\begin{tabular}{|c|c|c|c|c|c|c|}
\hline \multirow[b]{2}{*}{ BMI $\left(\mathrm{kg} / \mathrm{m}^{2}\right)$} & \multicolumn{2}{|l|}{$\geqslant 1 \mathrm{~mm}$} & \multicolumn{2}{|l|}{$\geqslant 1.5 \mathrm{~mm}$} & \multicolumn{2}{|l|}{ Increase in K\&L } \\
\hline & Progression (\%) & OR $(95 \% \mathrm{Cl})$ & Progression (\%) & OR $(95 \% \mathrm{Cl})$ & Progression (\%) & OR $(95 \% \mathrm{Cl})$ \\
\hline$\leqslant 25$ & 9.1 & 1 & 2.0 & 1 & 8.9 & 1 \\
\hline$>25-27.5$ & 8.0 & 0.9 (0.6 to 1.3$)$ & 2.6 & $1.5(0.6$ to 3.8$)$ & 9.5 & $1.1(0.8$ to 1.6$)$ \\
\hline$>27.5$ & 9.1 & $0.9(0.6$ to 1.3$)$ & 3.2 & $1.5(0.6$ to 3.7$)$ & 12.3 & $1.3(0.9$ to 1.8$)$ \\
\hline
\end{tabular}

BMI, body mass index; K\&L, Kellgren and Lawrence.

ORs were adjusted for age, sex and follow-up time.

Progression is defined by two definitions-namely a joint space narrowing of $\geqslant 1$, and $1.5 \mathrm{~mm}$ at follow-up, and by an increase of minimally 1 grade in K\&L index. 
younger and (possibly) healthier population, the number of cases with incident and progression of osteoarthritis at follow-up may have been underestimated. This could have resulted in an underestimation of the reported associations.

We argued whether the reported estimates could be flawed by limited contrast between those people with a BMI $>27.5 \mathrm{~kg} / \mathrm{m}^{2}$ compared with those with a BMI $\leqslant 25 \mathrm{~kg} / \mathrm{m}^{2}$. In our study population, only a few people had a BMI $>30 \mathrm{~kg} / \mathrm{m}^{2}$. Additionally, we assessed the association of a BMI $>30 \mathrm{~kg} / \mathrm{m}^{2}$ with the incidence and progression of osteoarthritis, compared with those with a BMI $\leqslant 25 \mathrm{~kg} / \mathrm{m}^{2}$. We found similar estimates for the hip and knee; however, for JSN, it just failed to reach significance (95\% CI 0.8 to 9.9). Besides, it is plausible that if we had used a population with a higher BMI, the mean BMI of the highest group $\left(>27.5 \mathrm{~kg} / \mathrm{m}^{2}\right)$ would have been much higher. Consequently, the contrast between the reference group and this group would have been greater, with probably a higher risk estimate. We assume that the reported risk estimate in this study would have been even stronger in a population with a higher BMI.

A possible explanation for the difference between the knee and hip might be that the relationship between BMI and osteoarthritis is mediated by another local factor, such as changed mechanical loading of the joint by-for example, malalignment. Sharma et $\mathrm{al}^{33}$ and Felson et $\mathrm{al}^{34}$ reported that the relationship between obesity and osteoarthritis is modified by the presence of malalignment of the knee. In an earlier study, we did not find that a changed mechanical loading (acetabular dysplasia) of the hip distinctively modified the association between BMI and the onset of hip osteoarthritis. ${ }^{35}$ These results suggest that changed mechanical loading of the joint is an effect-modifier for the relationship between BMI and osteoarthritis for the knee but not for the hip. This difference might be explained by the difference in anatomy; the knee joint is a hinge joint, whereas the hip is a ball-and-socket joint. Although malalignment is per definition not a problem in a ball-andsocket joint (eg, the hip joint), it might be a problem in a hinge joint (eg, the knee joint). If the forces on the joint are higher because of higher stresses (eg, obesity, heavy lifting), forces in a malaligned hinge joint might even double or triple as compared with a normal aligned joint, owing to the smaller area that the forces act on.

The relationship between BMI and osteoarthritis could also be modified by trauma of the joint, particularly the knee joint. Englund and Lohmander ${ }^{36}$ reported that patients who had undergone total meniscectomy with obesity (BMI $\geqslant 30 \mathrm{~kg} / \mathrm{m}^{2}$ ) had a greater likelihood of knee ROA than those with a BMI $<25 \mathrm{~kg} / \mathrm{m}^{2}$.

Besides the biomechanical effects, there also seems to be a systemic metabolic effect of obesity that influences the onset or progression of osteoarthritis. Leptin, a small polypeptide that regulates food intake and energy expenditure at the hypothalamic level, may provide the metabolic link between obesity and osteoarthritis. Plasma levels of leptin strongly correlate with fat mass, and levels fall after weight loss. ${ }^{37}$ Recent studies detected functional leptin receptors on human adult articular chondrocytes. $^{38}{ }^{39}$ Leptin may also play a part in the development of osteoarthritis through changes in the bony matrix. ${ }^{40} 41$ As obesity and osteoarthritis are both associated with genetic predispositions, these two dispositions may be linked. However, Manek et $a l^{42}$ could not detect a shared genetic pathway between BMI and knee osteoarthritis.

However, this possible systemic effect of obesity does not explain why obesity is related to knee osteoarthritis and hardly at all to hip osteoarthritis.

The distinction between the incidence and progression of already existing osteoarthritis is arbitrary. This distinction depends on the point during the ongoing process of degenerative changes in the joint at which the cut-off point of the present osteoarthritis is defined..$^{43}$ If osteoarthritis is diagnosed earlier in the future, because of more sensitive diagnostic tools, cases formerly considered to be "incident cases" will then be considered as "progressive cases". In the case of the Kellgren and Lawrence index, incident ROA is usually defined as minimally grade 2 at follow-up and grade 0 or 1 at baseline. However, one can question whether the cut-off point of $\geqslant$ grade 2 is valid and whether it is correct to classify people with grade 1 as "normal". Recently Hart and Spector ${ }^{44}$ investigated whether the Kellgren and Lawrence grade 1 of the knee was a reliable indicator of knee osteoarthritis in a longitudinal population-based study. After 10 years of follow-up, $>60 \%$ of the participants with grade 1 at baseline had developed grade $\geqslant 2$, whereas $20 \%$ of those with a Kellgren and Lawrence grade 0 at baseline had developed a grade $\geqslant 2$. For the hip, we found that after 6 years of follow-up, $7.6 \%$ of participants with a Kellgren and Lawrence hip grade $1 v 1.4 \%$ with grade 0 at baseline developed a grade $\geqslant 2$. These results suggest that the cut-off point of $\geqslant$ grade 2 for the hip seems to be valid, whereas a cut-off point of $\geqslant$ grade 1 for the knee seems more appropriate. Overall, the distinction between incident ROA and progression of ROA seems arbitrary. Owing to the absence of consensus on how to define progression, we used two definitions in this study-namely JSN $\geqslant 1$ and $\geqslant 1.5 \mathrm{~mm}$, and also an increase of minimally 1 grade in the Kellgren and Lawrence index. We believe that a better insight into the consistency of reported results is possible with the use of several cut-off points.

In this study, we included those knees and hips with a presence of radiographic osteoarthritic signs at baseline defined by a Kellgren and Lawrence score at baseline of grade 1, 2 or 3 for the progression analyses. Additionally, we repeated these analyses for those knee and hips with a Kellgren and Lawrence score of grade 2 or 3 at baseline. All assessed ORs remain similar to those reported in tables 3 and 4; however, owing to lower numbers, the risk estimates failed to reach significance.

On the basis of the results of this study, we conclude that $\mathrm{BMI}$ is associated with the incidence and progression of knee ROA, and that these associations are independent of age and sex. Furthermore, it seems that BMI is not associated with the incidence and progression of hip ROA.

\section{ACKNOWLEDGEMENTS}

We thank F van Rooij, E van der Heijden, R Vermeeren and L Verwey for collection of follow-up data. We also thank the participating general practitioners, the many field workers at the research centre in Ommoord and, of course, all participants.

\section{Authors' affiliations \\ M Reijman, Department of Epidemiology and Biostatistics, Rotterdam, The Netherlands \\ A P Bergink, Department of Orthopedics, Erasmus Medical Center, Rotterdam, The Netherlands \\ H A P Pols, A P Bergink, Department of Internal Medicine, Erasmus Medical Center, Rotterdam, The Netherlands \\ J M W Hazes, Department of Rheumatology, Erasmus Medical Center, Rotterdam, The Netherlands \\ J N Belo, A M Lievense, S M A Bierma-Zeinstra, Department of General Practice, Erasmus Medical Center, Rotterdam, The Netherlands \\ Competing interests: None. \\ $M R$ and $S M A B-Z$ had the idea for the study. MR and $S M A B-Z$ managed the study. MR, HAPP, AML and SMAB-Z were responsible for the analysis and interpretation of the data. All authors commented on the paper. \\ Ethical approval: Ethical approval was obtained from the medical ethics committee of the Erasmus Medical Center.}




\section{REFERENCES}

1 Felson DT, Zhang Y. An update on the epidemiology of knee and hip osteoarthritis with a view to prevention. Arthritis Rheum 1998;41:1343-55.

2 Felson DT, Lawrence RC, Dieppe PA, Hirsch R, Helmick CG, Jordan JM, et al. Osteoarthritis: new insights. Part 1: the disease and its risk factors. Ann Intern Med 2000;133:635-46.

3 Felson DT. An update on the pathogenesis and epidemiology of osteoarthritis. Radiol Clin N Am 2004;42:1-9.

4 Spector TD, Hart DJ, Doyle DV. Incidence and progression of osteoarthritis in women with unilateral knee disease in the general population: the effect of obesity. Ann Rheum Dis 1994:53:565-8.

5 Manninen P, Riihimaki H, Heliovaara M, Makela P. Overweight, gender and knee osteoarthritis. Int J Obesity 1996;20:595-7.

6 Coggon D, Reading I, Croft P, McLaren M, Barrett D, Cooper C. Knee osteoarthritis and obesity. Int J Obes Relat Metab Disord 2001;25:622-7.

7 Yoshimura N, Nishioka S, Kinoshita H, Hori N, Nishioka T, Ryujin M, et al. Risk factors for knee osteoarthritis in Japanese women: heavy weight, previous joint injuries, and occupational activities. J Rheumatol 2004;31:157-62.

8 Sandmark $H$, Hogstedt C, Lewold S, Vingard E. Osteoarthritis of the knee in men and women in association with overweight, smoking and hormone therapy. Ann Rheum Dis 1999:58:151-5.

9 Kohatsu ND, Schurman DJ. Risk factors for the development of osteoarthritis of the knee. Clin Orthop Relat Res 1990;261:242-6.

10 Hart DJ, Doyle DV, Spector TD. Incidence and risk factors for radiographic knee osteoarthritis in middle-aged women: the Chingford Study. Arthritis Rheum 1999:42:17-24

11 Hochberg M, Lethbridge-Cejku M, Scott WW Jr, Reichle R, Plato CC, Tobin JD. The association of body weight, body fatness and body fat distribution with osteoarthritis of the knee: data from the Baltimore Longitudinal Study of Aging. J Rheumatol 1995;22:488-93.

12 Cicuttini FM, Spector TD, Baker J. Risk factors for osteoarthritis in the tibiofemoral and patellofemoral joints of the knee. J Rheumatol 1997;24:1164-7.

13 Lievense AM, Bierma-Zeinstra SMA, Verhagen AP, Baar ME van, Verhaar JAN, Koes BW. Influence of obesity on the development of osteoarthritis of the hip: a systematic review. Rheumatology 2002;41:1155-62.

14 Gelber AC, Hochberg MC, Mead LA, Wang NY, Wigley FM, Klag MJ. Body mass index in young men and the risk of subsequent knee and hip osteoarthritis. Am J Med 1999;107:542-8.

15 Gelber AC. Obesity and hip osteoarthritis: the weight of the evidence is increasing. Am J Med 2003;114:158-9.

16 Oliveria SA, Felson DT, Cirillo PA, Reed J, Walker AM. Body weight, body mass index, and incident symptomatic osteoarthritis of the hand, hip, and knee. Epidemiology 1999; 10:161-6.

17 Olsen O, Vingard E, Koster M, Alfredsson L. Etiologic fractions for physical work load, sports and overweight in the occurrence of coxarthrosis. Scand J Work Environ Health 1994;20:184-8.

18 Vingard E. Overweight predisposes to coxarthrosis. Body-mass index studied in 239 males with hip arthroplasty. Acta Orthop Scand 1991;62:106-9.

19 Cooper C, Snow S, McAlindon TE, Kellingray S, Stuart B, Coggon D, et al. Risk factors for the incidence and progression of radiographic knee osteoarthritis. Arthritis Rheum 2000;43:995-1000.

20 Dieppe P, Cushnaghan J, Young P, Kirwan J. Prediction of the progression of joint space narrowing of the knee by bone scintigraphy. Ann Rheum Dis 1993:52:557-63.

21 Ledingham J, Regan $M$, Jones A, Doherty M. Factors affecting radiographic progression of knee osteoarthritis. Ann Rheum Dis 1995;54:53-8.

22 Miyazaki T, Wada M, Kawahara H, Sato M, Baba H, Shimada S. Dynamic load at baseline can predict radiographic disease progression in medial compartment knee osteoarthritis. Ann Rheum Dis 2002;61:617-22.
23 Schouten JS, van den Ouweland FA, Valkenburg HA. A 12 year follow up study in the general population on prognostic factors of cartilage loss in osteoarthritis of the knee. Ann Rheum Dis 1992;51:932-7.

24 Wolfe $F$, Lane NE. The long term outcome of osteoarthritis: rates and predictors of joint space narrowing in symptomatic patients with knee osteoarthritis. $J$ Rheumatol 2002;29:139-46.

25 Lievense AM, Bierma-Zeinstra SMA, Verhagen AP, Verhaar JAN, Koes BW. Prognostic factors of progress of osteoarthritis of the hip: a systematic review. Arthritis Rheum 2002;47:556-62.

26 Hofman A, Grobbee DE, de Jong PT, van den Ouweland FA. Determinants of disease and disability in the elderly: the Rotterdam Elderly Study. Eur J Epidemiol 1991;7:403-22.

27 Reijman M, Hazes JMW, Pols HAP, Bernsen RMD, Koes BW, BiermaZeinstra SMA. Role of radiography in predicting progression of osteoarthritis of the hip: prospective cohort study. BMJ 2005;330:1183.

28 Auleley G, Girardeau B, Dougados M, Ravaud P. Radiographic assessment of hip osteoarthritis progression: impact of reading procedures for longitudinal studies. Ann Rheum Dis 2000:59:422-7.

29 Croft P, Cooper C, Wickham C, Coggon D. Defining osteoarthritis of the hip for epidemiologic studies. Am J Epidemiol 1990;132:514-22.

30 Odding E, Valkenburg HA, Algra D, Vandenouweland FA, Grobbee DE, Hofman A. Associations of radiological osteoarthritis of the hip and knee with locomotor disability in the Rotterdam Study. Ann Rheum Dis 1998:57:203-8.

31 Bergink AP, Uitterlinden AG, Van Leeuwen JP, Hofman A, Verhaar JA, Pols HA. Bone mineral density and vertebral fracture history are associated with incident and progressive radiographic knee osteoarthritis in elderly men and women: the Rotterdam Study. Bone 2005; 37:446-56.

32 Zhang Y, Glynn RJ, Felson DT. Musculoskeletal disease research: should we analyze the joint or the person? J Rheumatol 1996;23:1130-4

33 Sharma L, Lou C, Cahue S, Dunlop DD. The mechanism of the effect of obesity in knee osteoarthritis: the mediating role of malalignment. Arthritis Rheum 2000:43:568-75.

34 Felson DT, Coggins J, Niu J, Zhang Y, Hunter DJ. The effect of body weight on progression of knee osteoarthritis is dependent on malalignment. Arthritis Rheum 2004;50:3904-9.

35 Reijman M, Hazes JMW, Pols HAP, Bernsen RMD, Koes BW, BiermaZeinstra SMA. Acetabular dysplasia predicts incident osteoarthritis of the hip: the Rotterdam Study. Arthritis Rheum 2005;52:787-93.

36 Englund M, Lohmander LS. Risk factors for symptomatic knee osteoarthritis fifteen to twenty-two years after meniscectomy. Arthritis Rheum 2004;50:2811-19.

37 Friedman JM, Halaas JL. Leptin and the regulation of body weight in mammals. Nature 1998;395:763-70.

38 Figenschau Y, Knutsen G, Shahazeydi S, Johansen O, Sveinbjornsson B. Human articular chondrocytes express functional leptin receptors. Biochem Biophys Res Commun 2001;287:190-7.

39 Dumond H, Presle N, Terlain B, Mainard D, Loeville D, Netter P, et al. Evidence for a key role of leptin in osteoarthritis. Arthritis Rheum 2003;48:31 18-28.

40 Ducy $\mathbf{P}$, Amling M, Takeda S, Priemel M, Schillimg AF, Beil FT, et al. Leptin inhibits bone formation through a hypothalamic relay: a central control of bone mass. Cell 2000;100:197-207.

41 Aspden RM, Scheven BAA, Hutchinton JD. Osteoarthritis as a systemic disorde including stromal cell differentiation. Lancet 2001;357:1118-20.

42 Manek NJ, Hart D, Spector TD, MacGregor AJ. The association of body mass index and osteoarthritis of the knee joint. Arthritis Rheum 2003:48:1024-9.

43 Lohmander LS, Felson DT. Can we identify a 'high risk' patient profile to determine who will experience rapid progression of osteoarthritis? Osteoarthritis Cartilage 2004;12(Suppl A):S49-52.

44 Hart DJ, Spector TD. Kellgren \& Lawrence grade 1 osteophytes in the kneedoubtful or definite? Osteoarthritis Cartilage 2003;11:149-50. 